décrépitude des roças leur a retiré leur statut d'Européens de seconde classe. Certains regrettent même le «temps des patrons ». De quoi faire frémir un Santoméen de souche! Le deuxième volume analyse les conditions prévalant dans les années 1950-1970 qui obligèrent ces contratados à quitter Mindelo pour aller travailler sous l'équateur, ce qu'il est convenu d'appeler la pior migração. Et en fait, le peu que nous avons vu ( $c f$. René Pélissier, Explorar, Orgeval, Éditions Pélissier, 1979) de la vie des Capverdiens à São Tomé et à Príncipe en 1966 nous a vite confirmé que ces deux îles, même à la fin de l'époque coloniale, ne pouvaient être tenues pour des destinations de choix par les misérables de São Vicente, chassés par le spectre de la faim. On était encore loin de Gilberto Freyre et de la propagande officielle.

12 mai 2009, René Pélissier

\title{
John S. SAUL, Decolonization and Empire. Contesting the Rhetoric and Reality of Resubordination in Southern Africa and Beyond, Monmouth
} (Wales), Merlin Press/Johannesbourg, Wits University Press, 2008, ii + 201 p., ISBN : 978-1-86814-468-6.

Prudence dans le choix de notre vocabulaire : un mauvais coup est vite arrivé ! Sera-ce une égratignure pour simple plumitif ? Un coup de pied dans le fondement, suffisant pour un vulgaire déviationniste? Ou, moins probable, une éventration royale suivie d'une de ces autopsies en règle, réservées aux adversaires vraiment récalcitrants? L'auteur est un de ces frères prêcheurs de l'Évangile selon saint Marx, en mission, prolongée ou intermittente, pendant les années mi-1960mi-1980, les «vingt glorieuses » du socialisme mozambicain dans sa phase porteuse d'espérance. Idéologue et polémiste redoutable, brillant universitaire canadien, il a réuni dans ce recueil des articles publiés, des textes de conférence, etc., le tout étant orienté vers une certaine nostalgie de sa jeunesse militante, d'abord à Dares-Salam, puis dans ces milieux où des intellectuels étrangers s'efforçaient, à Maputo, de fournir aux cadres du Frelimo une armature doctrinale fondée sur les saintes Écritures. De proprement mozambicains, on ne trouve que deux chapitres partiels et une vingtaine de pages en annexe où il honore la mémoire d'Eduardo Mondlane et, ce qui est plus attendu, de Samora Machel, le reste - c'està-dire l'essentiel - du livre étant consacré à une démolition du capitalisme, de la mondialisation et de certains auteurs anglophones qui ont eu le malheur de ne pas épouser ses thèses. Pour être équitable avec cet infatigable bretteur, ajoutons qu'il ne se prive pourtant pas de plusieurs critiques - postérieures - à l'égard de la politique autoritaire du Frelimo. Donc, on lui reconnaîtra volontiers une constante : la fidélité à Marx, même si ses adeptes ont eu - semble-t-il - quelque mal à l'interpréter correctement sous la Croix du Sud, ces dernières années. Quant au contexte sociétal et aux contraintes locales, pourquoi s'en soucier quand on a la Foi et des missionnaires aptes à la propager? 